\title{
A step test to assess exercise-related oxygen desaturation in interstitial lung
} disease

\author{
S. Dal Corso, S.R. Duarte, J.A. Neder, C. Malaguti, M.B. de Fuccio, \\ C.A. de Castro Pereira and L.E. Nery
}

ABSTRACT: A 6-min step test (6MST) may constitute a practical method for routinely assessing effort tolerance and exercise-related oxyhaemoglobin desaturation (ERD) in the primary care of patients with interstitial lung disease.

In total, 31 patients (19 males) with idiopathic pulmonary fibrosis $(n=25)$ and chronic hypersensitivity pneumonia were submitted, on different days, to two 6MSTs. Physiological responses were compared with those found on maximal and submaximal cycle ergometer tests at the same oxygen uptake $\left(\mathrm{V}^{\prime} \mathrm{O}_{2}\right)$. Chronic breathlessness was also determined, as measured by the baseline dyspnoea index (BDI).

Responses to 6MST were highly reproducible: $1.3 \pm 2.0$ steps $\cdot \mathrm{min}^{-1}, \pm 5$ beats $\cdot \mathrm{min}^{-1}$ (cardiac frequency), $\pm 50 \mathrm{~mL} \cdot \mathrm{min}^{-1}\left(V^{\prime} \mathrm{O}_{2}\right), \pm 7 \mathrm{~L} \cdot \mathrm{min}^{-1}$ (minute ventilation) and $\pm 2 \%$ (arterial oxygen saturation measured by pulse oximetry $\left.\left(\mathrm{Sp}, \mathrm{O}_{2}\right)\right)$. The number of steps climbed in 6 min was correlated to peak $\mathrm{V}^{\prime} \mathrm{O}_{2}$ and the $\mathrm{BDI}$. There were significant associations among the tests in relation to presence (change in $\mathrm{Sp}, \mathrm{O}_{2}$ between rest and exercise $\geqslant 4 \%$ ) and severity $\left(\mathrm{Sp}, \mathrm{O}_{2}<88 \%\right)$ of ERD. Four patients, however, presented ERD only in response to 6MST. Resting diffusing capacity of the lung for carbon monoxide and alveolar-arterial oxygen tension difference were the independent predictors of the number of steps climbed.

A single-stage, self-paced 6-min step test provided reliable and reproducible estimates of exercise capacity and exercise-related oxyhaemoglobin desaturation in interstitial lung disease patients.

KEYWORDS: Exercise induced, exercise tests, interstitial lung diseases, oxygen saturation, oxygen uptake, pulmonary dysfunction

\footnotetext{
(
} mpaired gas exchange, especially during exertion, is a hallmark of advanced interstitial lung disease (ILD) [1, 2]. Functional measurements at rest may not be precise in determining the presence and extent of exercise-related oxyhaemoglobin desaturation (ERD) in the patient population [3].

Stepping was first used as a modality of exercise evaluation in the early 1940s [4]. Over the past few decades, step tests have been shown to be clinically useful in estimating exercise tolerance [5], in evaluating the risk of post-operative complications [6] and in assessing effort-related hypoxaemia in different disease states [7]. For this latter purpose, stepping is particularly attractive since it requires a minimum of space and technical expertise, especially if used in association with pulse oximetry [7]. In addition, a higher metabolic demand has been found during step tests as compared with other "field" tests in chronic obstructive pulmonary disease (COPD) and cystic fibrosis, but with a similar fall in arterial oxygen saturation [8-10]. No previous study, however, has prospectively investigated the clinical role of a step test in evaluating ERD and exercise tolerance in ILD.

Therefore, the aim of the present study was to determine whether a single-stage, self-paced, 6min step test (6MST) provides reliable and reproducible estimates of ERD and exercise capacity in patients with fibrotic ILD. The ultimate goal was to develop an inexpensive and portable test that could be easily used in primary-care settings as part of the routine medical evaluation of the patient population.

\section{METHODS AND MATERIALS}

\section{Subjects}

For participation in the present study, subjects $(n=$ 45) were initially recruited from the ILD outpatient
AFFLLIATIONS

Pulmonary Function and Clinical Exercise Physiology Unit (SEFICE), Division of Respiratory Diseases, Federal University of São Paulo (UNIFESP), São Paulo, Brazil.

\section{CORRESPONDENCE}

J.A. Neder

Respiratory Division

Dept of Medicine

Federal University of São Paulo

Paulista School of Medicine (UNIFESP-EPM)

Rua Francisco de Castro 54

Vila Clementino

CEP 04020-050

São Paulo

Brazil

Fax: 551155752843

E-mail: albneder@pneumo.epm.br

Received:

July 172006

Accepted after revision:

September 182006

SUPPORT STATEMENT

This study was supported by CAPES (Coordenadoria de Aperfeiçoamento do Pessoal de Nível Superior) and FAPESP (Fundação de Amparo à Pesquisa do Estado de São Paulo, São Paulo, Brazil). J.A. Neder is an Established Investigator (level II) of the Conselho Nacional de Desenvolvimento Científico e Tecnológico (CNPq), Brazil.

STATEMENT OF INTEREST None declared.

Online ISSN 1399-3003 
clinic of the hospital. Clinical and functional stability was confirmed by the absence of change in medication dosage and forced vital capacity (FVC) values $( \pm 5 \%)$ in the preceding 3 months. Inclusion criteria were as follows: 1) presence of diffuse interstitial infiltrate on high-resolution computed tomography with evidence of pulmonary fibrosis; 2) forced expiratory volume in one second/FVC $>70 \%$ with reduced FVC (below the lower limit of normality) and/or decreased single-breath diffusing capacity of the lung for carbon monoxide (DL,CO); and 3) resting arterial oxygen saturation measured by pulse oximetry $\left(\mathrm{Sp}, \mathrm{O}_{2}\right.$; Biox 3740; Ohmeda, Boulder, CO, USA) $\geqslant 90 \%$ in room air. None of the subjects were receiving long-term oxygen therapy.

During the study, 14 patients were excluded due to respiratory infections or exacerbation of the underlying disease. The final sample comprised 31 patients (19 males, aged 34-79 yrs), 25 with idiopathic pulmonary fibrosis (IPF) and six with biopsyproven chronic hypersensitivity pneumonia. A total of 14 (56\%) patients with IPF underwent open lung biopsy and presented with the pattern of usual interstitial pneumonia. Diagnosis of IPF in the remaining patients was performed according to the clinical criteria suggested by the American Thoracic Society (ATS)/European Respiratory Society [11]. All subjects gave written informed consent, which was previously approved by the institutional medical ethics committee.

\section{Study design}

All patients initially rated their level of chronic breathlessness (baseline dyspnoea index (BDI)) [12] and underwent rampincremental cycle ergometer cardiopulmonary exercise testing (CPETmax). After a resting period $(1 \mathrm{~h})$, patients performed a $6 \mathrm{MST}$ with metabolic and ventilatory measurements. On another day (48 h apart), patients underwent a constant work-rate (WR) test (CPETsubmax) at the same metabolic stress, i.e. at the same pulmonary oxygen uptake $\left(V^{\prime} \mathrm{O}_{2}\right)$, of the $6 \mathrm{MST}$. After $1 \mathrm{~h}$, the $6 \mathrm{MST}$ was repeated.

\section{Measurements}

\section{Pulmonary function tests}

Spirometric tests without bronchodilators were performed on the CPF-System (Medical Graphics Corporation, St Paul, MN, USA). Static lung volumes were determined by breath-bybreath open-circuit nitrogen washout (PF-DX System; Medical Graphics Corporation). DL,CO was measured by the modified Krogh technique (PF-DX System; Medical Graphics Corporation). Absolute values were compared with theoretical values for the adult Brazilian population [13-15]. Arterial blood samples were obtained from radial artery puncture in standard anaerobic conditions (ABL 330; Radiometer, Copenhagen, Denmark).

\section{Cardiopulmonary exercise testing}

The exercise tests were performed in room air. They were carried out on an electromagnetically braked cycle ergometer (CPE 2000; Medical Graphics Corporation). The following data were obtained breath by breath (MGC-CPX System; Medical Graphics Corporation) and were expressed as 15-s averages: $V^{\prime} \mathrm{O}_{2}$ and pulmonary carbon dioxide production $\left(V^{\prime} \mathrm{CO}_{2}\right)$; minute ventilation $\left(V^{\prime} \mathrm{E}\right)$; tidal volume $(V \mathrm{~T})$; respiratory rate; and ventilatory equivalents for oxygen and carbon dioxide
$\left(V^{\prime} \mathrm{E} / V^{\prime} \mathrm{O}_{2}\right.$ and $\left.V^{\prime} \mathrm{E} / V^{\prime} \mathrm{CO}_{2}\right)$. ECG tracings and cardiac frequency $(f C)$ were recorded continuously: oxygen pulse $\left(V^{\prime} \mathrm{O}_{2} /\right.$ $f C)$ was calculated. Subjects were asked to rate "shortness of breath" and "leg effort" at exercise cessation by using the $0-10$ Borg's category-ratio scale.

A value of resting $S_{\mathrm{p}}, \mathrm{O}_{2}-$ lowest $S_{\mathrm{p}, \mathrm{O}_{2}}\left(\Delta \mathrm{Sp}_{\mathrm{p}} \mathrm{O}_{2}\right) \geqslant 4 \%$ was considered indicative of ERD [7]. Supplemental oxygen was not administered unless $\mathrm{Sp}, \mathrm{O}_{2}$ was $<80 \%$ and there was intense distress or breathlessness and/or a clinical indication was present, as judged by the accompanying laboratory physician. If supplemental oxygen was required, the subject was excluded as accurate $V^{\prime} \mathrm{O}_{2}$ measurements were needed in the present study.

\section{Incremental exercise test}

During the CPETmax, the WR was continuously increased in a linear "ramp" pattern (5-15 W· $\left.\mathrm{min}^{-1}\right)$ and was individually selected in such a way that the ramp duration was $>8$ and $<12 \mathrm{~min}$. Peak $V^{\prime} \mathrm{O}_{2}$ values were compared with those predicted by NEDER et al. [16].

\section{Constant WR exercise test}

The CPETsubmax was performed at a previously selected WR to achieve a similar $V^{\prime} \mathrm{O}_{2}$ to the 6MST. Considering that the metabolic cost of stationary cycle ergometry at a given pedalling rate depends on the external power output and the body mass actually displaced (i.e. that of the legs), leg masses (LM) were estimated from body weight using the following sex-specific equations [17]:

$$
\begin{aligned}
& \mathrm{LM} \text { males in } \mathrm{kg}=(0.231 \times \text { weight in } \mathrm{kg})+6.78 \\
& \mathrm{LM} \text { females in } \mathrm{kg}=(0.334 \times \text { weight in } \mathrm{kg})-0.41
\end{aligned}
$$

The WR needed to generate a given $V^{\prime} \mathrm{O}_{2}$ was then estimated as [17]:

$$
\mathrm{WR}=\left(V^{\prime} \mathrm{O}_{2} \text { in } \mathrm{mL} \cdot \mathrm{min}^{-1}-(16.8 \times \mathrm{LM})+75\right)-10.6
$$

\section{6-min step test}

The 6MST was performed on a $20 \mathrm{~cm}$-high, single-step device with no handles. The general principles of the test were based on the current ATS/American College of Chest Physicians recommendations for the 6-min walking test (6MWT) [18]. Patients were instructed to walk up and down the platform as fast as possible during a 6-min period. They were also told that they could slow down if necessary and even make stops for resting. Standardised encouragement was given each minute (e.g. "you are doing well, keep going") using an even tone of voice. Patients were also told every minute for how long they still had to climb the step. Patients established their own cadence. The number of steps $\cdot \min ^{-1}$ (i.e. the rate of stepping) was recorded. The same computer-based system described in the Cardiopulmonary exercise testing section was used to record metabolic and ventilatory variables. $\mathrm{Sp}, \mathrm{O}_{2}$ values were obtained as previously described.

\section{Data analysis}

Data are presented as mean \pm SD or median (range) for variables with parametric and nonparametric distributions, respectively. One-way ANOVA (with post hoc Bonferroni) or Friedman's test were used to evaluate differences among the 
tests. Pearson's product-moment coefficients assessed linear association. Agreement between 6MST replicates or between test modalities was evaluated by the Bland-Altman procedure. Chi-squared (Fisher exact) test was used to evaluate the association between categorical data. Backward stepwise multiple regression analysis was used to determine the resting predictors of the number of steps climbed in the 6MST. The probability of a type I error was set at $5 \%(p<0.05)$.

\section{RESULTS}

\section{Sample characteristics}

On average, patients presented with mild-to-moderate restrictive dysfunction with low DL,CO values, which were typically proportional to the level of lung volume reduction (table 1). As expected, peak aerobic capacity was reduced as compared with the predicted values (peak $V^{\prime} \mathrm{O}_{2}=69.9 \pm 14.9 \%$ predicted),

\begin{tabular}{|c|c|}
\hline Variables & Values \\
\hline \multicolumn{2}{|c|}{ Demographic and anthropometric } \\
\hline Males/females $\mathrm{n}$ & $19 / 12$ \\
\hline Age yrs & $58 \pm 11$ \\
\hline Body mass index $\mathrm{kg} \cdot \mathrm{m}^{-2}$ & $26.2 \pm 2.9$ \\
\hline \multicolumn{2}{|l|}{ Clinical and smoking history } \\
\hline \multicolumn{2}{|l|}{ Dyspnoea } \\
\hline Duration months & $36(4-120)$ \\
\hline Baseline dyspnoea index & $9(6-12)$ \\
\hline \multicolumn{2}{|l|}{ Smoking } \\
\hline Ex-smokers & $14(45.2)$ \\
\hline Pack-yrs & $21.2 \pm 10.7$ \\
\hline \multicolumn{2}{|l|}{ Pulmonary function } \\
\hline \multicolumn{2}{|l|}{ Spirometry } \\
\hline FVC L & $2.5 \pm 0.7$ \\
\hline FVC $\%$ pred & $77.3 \pm 18.1$ \\
\hline FEV 1 L & $2.1 \pm 0.6$ \\
\hline FEV $1 \%$ pred & $77.6 \pm 19.0$ \\
\hline FEV $1 / F V C$ & $82.0 \pm 6.6$ \\
\hline \multicolumn{2}{|l|}{ Static lung volumes } \\
\hline TLC L & $4.1 \pm 1.1$ \\
\hline TLC \% pred & $71.8 \pm 15.8$ \\
\hline \multicolumn{2}{|l|}{ Lung diffusing capacity } \\
\hline$D \mathrm{~L}, \mathrm{CO} \mathrm{mL} \cdot \mathrm{min}^{-1} \cdot \mathrm{mmHg}^{-1}$ & $14.8 \pm 5.8$ \\
\hline$D\llcorner, C O \%$ pred & $49.8 \pm 17.6$ \\
\hline$D\llcorner, \mathrm{CO} / \mathrm{VA} \%$ pred & $84.0 \pm 20.5$ \\
\hline \multicolumn{2}{|l|}{ Gas exchange } \\
\hline $\mathrm{Pa}_{1} \mathrm{O}_{2} \mathrm{mmHg}$ & $78.2 \pm 9.7$ \\
\hline $\mathrm{PA}-\mathrm{a}, \mathrm{O}_{2} \mathrm{mmHg}$ & $10(1-36.5)$ \\
\hline $\mathrm{Sa}, \mathrm{O}_{2} \%$ & $95 \pm 2$ \\
\hline $\mathrm{Sp}, \mathrm{O}_{2} \%$ & $94 \pm 3$ \\
\hline
\end{tabular}

Data are presented as mean $\pm \mathrm{SD}$, median (range) or $\mathrm{n}(\%)$, unless otherwise stated. FVC: forced vital capacity; \% pred: \% predicted; FEV1: forced expiratory volume in one second; TLC: total lung capacity; $D L, C O$ : diffusing capacity of the lung for carbon monoxide; $V_{\mathrm{A}}$ : alveolar volume; $\mathrm{Pa}_{\mathrm{a}} \mathrm{O}_{2}$ : arterial oxygen tension; $\mathrm{PA}-\mathrm{a}, \mathrm{O}_{2}$ : alveolar-arterial oxygen tension; $\mathrm{Sa}, \mathrm{O}_{2}$ : arterial oxygen saturation; $\mathrm{Sp}, \mathrm{O}_{2}$ : arterial oxygen saturation measured by pulse oximetry. $1 \mathrm{mmHg}=0.133 \mathrm{kPa}$. with 25 out of 31 patients presenting with peak $V^{\prime} \mathrm{O}_{2}$ values below the lower limit of normality.

\section{Reproducibility of the step tests}

All patients were able to successfully complete the step tests without complications; supplemental oxygen was not needed in any patient. Two patients, however, showed very low levels of $\mathrm{Sp}, \mathrm{O}_{2}$ (slightly $<80 \%$; fig. 1) Supplemental oxygen was not administered as these patients did not present intense dyspnoea and the ECG tracing was within normal limits (see Methods and materials section). There were no significant between-test differences on the total number of steps climbed and the rate of climbing: mean bias $\pm 95 \%$ confidence interval (CI) of the differences was $1.1 \pm 1.5$ and $1.3 \pm 2.0 \mathrm{steps} \cdot \mathrm{min}^{-1}$, respectively. Similarly, $f \mathrm{C}, V^{\prime} \mathrm{O}_{2}, \mathrm{Sp}_{\mathrm{p}} \mathrm{O}_{2}$ and $V^{\prime} \mathrm{E}$ did not differ between the tests more than \pm 5 beats $\cdot \mathrm{min}^{-1}, \pm 50 \mathrm{~mL}, \pm 1.5 \%$ and $\pm 7 \mathrm{~L} \cdot \mathrm{min}^{-1}$, respectively $(\mathrm{p}>0.05)$.

\section{Exercise-related desaturation}

There were no significant differences among the tests in relation to presence and severity of ERD (table 2). As shown in figure 1 , mean bias $\pm 95 \% \mathrm{CI}$ of the $S \mathrm{p}, \mathrm{O}_{2}$ differences between 6MST CPETmax and CPETsubmax were $-1.8 \pm 4.0$ and $-0.3 \pm 3.2 \%$, respectively. In total, 25 patients had significant ERD $\left(\Delta S \mathrm{p}, \mathrm{O}_{2} \geqslant 4 \%\right)$ during the CPETmax. Of these, 24 also presented ERD in response to the 6MST ( $\mathrm{p}<0.05)$. Similarly, 25 out of 26 patients who presented with ERD during the CPETsubmax showed significant desaturation in response to stepping $(\mathrm{p}<0.05 ;$ table 3$)$. Interestingly, however, four patients had ERD in response to 6MST but not in the CPETmax. Of these, three also did not desaturate in the CPETsubmax. Similarly, although there was a significant between-test association in relation to ERD severity, some patients desaturated below $88 \%$ only in response to the $6 \mathrm{MST}$

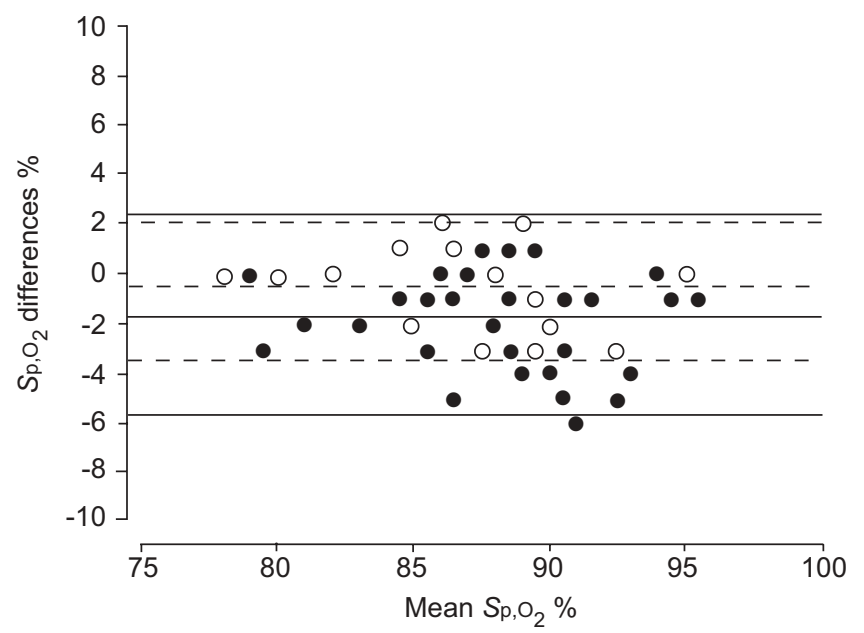

FIGURE 1. A Bland-Altman plot of the between-test differences on the nadir of arterial oxygen saturation measured by pulse oximetry $\left(\mathrm{Sp}, \mathrm{O}_{2}\right)$ in patients with interstitial lung disease. The $95 \%$ confidence intervals for the 6-min step test submaximal cardiopulmonary exercise test differences (6MST CPETsubmax; $\bigcirc$ ) were smaller than those found for 6MST maximal CPET (CPETmax; - ) mean bias $\pm 1.96 \mathrm{SD}$ for $6 \mathrm{MST}$ CPETmax data; --- : mean bias $\pm 1.96 \mathrm{SD}$ for $6 \mathrm{MST}$ CPETsubmax data. 
(table 3). There was a significant correlation between $\Delta S \mathrm{p}, \mathrm{O}_{2}$ with $V^{\prime} \mathrm{O}_{2}$ achieved in the $6 \mathrm{MST}(\mathrm{r}=0.78 ; \mathrm{p}<0.01)$.

\section{Physiological responses to stepping and cycling}

Stepping was associated with a near-maximum metabolic stress as compared with CPETmax (table 2). As shown in figure 2, mean bias $\pm 95 \% \mathrm{CI}$ of the between-test peak $V^{\prime} \mathrm{O}_{2}$ differences was only $-60 \pm 115 \mathrm{~mL} \cdot \mathrm{min}^{-1}$. Importantly, the total number of steps climbed was significantly related to both peak $V^{\prime} \mathrm{O}_{2}$ in the CPETmax and BDI $(\mathrm{r}=0.52$ and 0.55 , respectively; $\mathrm{p}<0.05)$.

No significant differences in the physiological adjustments were found between 6MST and CPETsubmax tests (at same $V^{\prime} \mathrm{O}_{2}$; table 2). However, there was a trend for higher $V^{\prime} \mathrm{CO}_{2} /$ $V^{\prime} \mathrm{O}_{2}$ and $V^{\prime} \mathrm{E} / V^{\prime} \mathrm{O}_{2}$ values during cycling as compared with stepping, i.e. $V^{\prime} \mathrm{CO}_{2}$ values tended to be higher at same metabolic demand during CPETsubmax than stepping (table 2).

\begin{tabular}{|c|c|c|c|}
\hline $\begin{array}{l}\text { Physiolc } \\
\text { step tes } \\
\text { cardiop } \\
\text { CPETma }\end{array}$ & $\begin{array}{l}\text { and percep } \\
\text { IST) and sub } \\
\text { hary exercise } \\
\text { sts }\end{array}$ & $\begin{array}{l}\text { ual response } \\
\text { maximal and } \\
\text { (CPETsubma }\end{array}$ & $\begin{array}{l}\text { s to 6-min } \\
\text { maximal } \\
\text { and }\end{array}$ \\
\hline Variables & 6MST & CPETsubmax & CPETmax \\
\hline \multicolumn{4}{|l|}{ Metabolic } \\
\hline$V^{\prime} \mathrm{O}_{2} L \cdot \mathrm{min}^{-1}$ & $0.98 \pm 0.22$ & $0.99 \pm 0.21$ & $1.09 \pm 0.30^{\#}$ \\
\hline$V^{\prime} \mathrm{O}_{2} \%$ maximal & $90.6 \pm 10.0$ & $91.3 \pm 9.5$ & \\
\hline$V^{\prime} \mathrm{CO}_{2} \mathrm{~L} \cdot \mathrm{min}^{-1}$ & $0.93 \pm 0.23$ & $1.07 \pm 0.27$ & $1.27 \pm 0.30^{\#}$ \\
\hline$R Q$ & $0.95 \pm 0.06$ & $1.06 \pm 0.09$ & $1.15 \pm 0.10^{\#}$ \\
\hline \multicolumn{4}{|l|}{ Ventilatory } \\
\hline$V^{\prime} E L \cdot \min ^{-1}$ & $44.1 \pm 10.2$ & $50.0 \pm 14.2$ & $60.7 \pm 14.5^{\#}$ \\
\hline$V^{\prime} E / V^{\prime} \mathrm{O}_{2}$ & $45.7 \pm 11.0$ & $51.3 \pm 14.1^{\circ}$ & $56.9 \pm 14.4^{\circ}$ \\
\hline$V^{\prime} \mathrm{E} / V^{\prime} \mathrm{CO}_{2}$ & $48.6 \pm 11.7$ & $47.6 \pm 12.3$ & $49.3 \pm 12.1$ \\
\hline$f R$ breaths $\cdot \min ^{-1}$ & $35 \pm 8$ & $37 \pm 10$ & $44 \pm 11^{\#}$ \\
\hline$V_{T} \mathrm{~L}$ & $1.28 \pm 0.33$ & $1.37 \pm 0.36$ & $1.43 \pm 0.39$ \\
\hline$V^{\prime} E / M V V$ & $0.46 \pm 0.17$ & $0.52 \pm 0.20$ & $0.62 \pm 0.21^{\#}$ \\
\hline \multicolumn{4}{|l|}{ Gas exchange } \\
\hline$\Delta \mathrm{Sp}, \mathrm{O}_{2} \%$ & $8(1-16)$ & $8(2-16)$ & $6(0-16)$ \\
\hline$\Delta S p, O_{2} N^{\prime} O_{2} \% \cdot L^{-1}$ & $8.2(0.7-21.6)$ & $7.3(1.4-21.0)$ & $5.2(0-20.3)^{+}$ \\
\hline$\Delta S p, O_{2} \geqslant 4 \%$ & 28 (90.3) & 26 (83.9) & $25(80.6)$ \\
\hline $\mathrm{Sp}, \mathrm{O}_{2}<88 \%$ & $14(45.2)$ & $13(41.9)$ & $12(38.7)$ \\
\hline \multicolumn{4}{|l|}{ Cardiovascular } \\
\hline $\mathrm{V}^{\prime} \mathrm{O}_{2} / \mathrm{fC} \mathrm{mL} \cdot \mathrm{min}^{-1} \cdot$ beat $^{-1}$ & $7.4 \pm 1.8$ & $7.4 \pm 1.7$ & $7.4 \pm 1.7$ \\
\hline$f_{C}$ beats $\cdot \mathrm{min}^{-1}$ & $135 \pm 14$ & $137 \pm 15$ & $150 \pm 14^{\#}$ \\
\hline fC \% pred & $84.4 \pm 8.4$ & $85.2 \pm 9.2$ & $93.9 \pm 9.1^{\#}$ \\
\hline \multicolumn{4}{|l|}{ Symptoms } \\
\hline Dyspnoea score & $4(0-10)$ & $4.5(0-10)$ & $7(0-10)^{\#}$ \\
\hline Leg effort score & $4.5(0-10)$ & $5(0-10)$ & $7(4-10)^{\#}$ \\
\hline
\end{tabular}

Data are presented as mean $\pm \mathrm{SD}$, median (range) or $\mathrm{n}(\%)$. $\mathrm{V}^{\prime} \mathrm{O}_{2}$ : oxygen uptake; $V^{\prime} \mathrm{CO}_{2}$ : carbon dioxide production; $\mathrm{RQ}$ : respiratory quotient; $V^{\prime} \mathrm{E}$ : minute ventilation; fR: respiratory frequency; $V_{T}$ : tidal volume; MVV: maximum voluntary ventilation; $\mathrm{Sp}_{\mathrm{O}_{2}}$ : arterial oxygen saturation measured by pulse oximetry; $\triangle \mathrm{Sp}_{\mathrm{O}} \mathrm{O}_{2}$ : resting $\mathrm{Sp}, \mathrm{O}_{2}$-lowest $\mathrm{Sp}_{1} \mathrm{O}_{2} ; \mathrm{fc}$ : cardiac frequency. $\mathrm{p}<0.05$ for $\#$ CPETmax $>6 \mathrm{MST}$ and CPETsubmax; ": CPETmax and CPETsubmax >6MST; CPETmax $<6 \mathrm{MST}$ and CPETsubmax.

\section{Determinants of performance in the 6MST}

In the present study, the physiological determinants of the exercise capacity in the 6MST (number of steps climbed) were also analysed. In a similar manner to other tests of functional capacity in ILD patients [19], DL,CO (\% pred) and alveolararterial oxygen tension difference $\left(\mathrm{PA}-\mathrm{a}, \mathrm{O}_{2}\right)$ were found to account for $40 \%\left(\mathrm{R}^{2}=0.40\right)$ of the variability in this outcome after a multiple regression analysis:

$$
\begin{gathered}
\text { Number of steps in the } 6 \mathrm{MST}=(0.59 \times \mathrm{DL}, \mathrm{CO})- \\
\left(0.88 \times \mathrm{PA}_{\mathrm{A}} \mathrm{a}, \mathrm{O}_{2} \text { in } \mathrm{mmHg}\right)+90.8
\end{gathered}
$$

\section{DISCUSSION}

The present study showed that a self-paced, single-stage 6MST can provide reproducible and reliable estimates of the presence and severity of pulmonary gas exchange impairment in patients with stable, mild-to-moderate fibrotic ILD. In addition, the total number of steps climbed (and the rate of climbing) was related to peak aerobic capacity and breathlessness in daily life. Therefore, the $6 \mathrm{MST}$ is a portable and inexpensive method to assess the current level of functional impairment and disability in the primary care of the patient population.

\section{Stepping as an ergometric modality}

The present study seems to constitute the first published investigation of the prospective validation of a step test in patients with fibrotic ILD. It was found that between-day reproducibility of the 6MST was very high (table 2 ). This was true not only for the physiological variables but also for the total "work" performed (as estimated by the number of steps climbed) and the rate of climbing. In this context, it could be hypothesised that, owing to the repetitive nature of the exercise movements, the patients tended to adopt a relatively constant rate of climbing throughout the test. Intra-individual variability of a number of physiological variables $\left(f \mathrm{C}, V^{\prime} \mathrm{O}_{2}\right.$, $S \mathrm{p}, \mathrm{O}_{2}$ and $V^{\prime} \mathrm{E}$ ) were also quite low and they compare well to those described in response to more traditional exercise tests in these patients [19]. An important aspect was the use of a single 20-cm step: lower steps may provide insufficient metabolic stress (i.e. the subjects would need to climb up faster, increasing the risk of falls) [4,5] and higher steps would prove too difficult to climb for older subjects with knee and hip problems.

The rationale for using a 6-min test was based on the wellvalidated 6MWT. It could be speculated, however, that a shorter test would improve patients' compliance and test safety. As mentioned, the rate of stepping was remarkably constant in all patients (table 2), suggesting that a 2-3-min test would also provide a reasonable estimate of exercise capacity [7]. Nevertheless, it is possible that peak $V^{\prime} \mathrm{O}_{2}$ was underestimated in these patients, especially considering ILD patients may present with very slow $V^{\prime} \mathrm{O}_{2}$ kinetics during exercise [20]. In addition, the nadir of $S \mathrm{p}, \mathrm{O}_{2}$ could not be reached in a test shorter than $6 \mathrm{~min}$ in duration, as ERD was significantly related to $V^{\prime} \mathrm{O}_{2}$ at exercise cessation, which has been found to increase progressively during the test (data not shown). Future studies are therefore needed to evaluate whether shorter step tests [7], even those using a different number of steps, are also clinically useful in the patient population. 


TABLE 3 Association between exercise-related oxygen
desaturation in response to 6-min step test
(6MST) and submaximal and maximal
cardiopulmonary exercise (CPETsubmax and
CPETmax) tests

\section{Clinical implications}

Abnormal gas exchange (hypoxaemia and increased alveolararterial gradient) plays a central role in limiting maximal exercise capacity in patients with ILD. In addition, ERD has been associated with health-related quality of life [21], pulmonary hypertension [22] and survival [23]. More recently, ERD during field tests, such as the 6MWT and the shuttle walk test, has been shown to be significantly related to survival in idiopathic interstitial pneumonia [20, 24, 25].

Routine assessment of ERD by such exercise field tests in primary-care settings, however, has been hampered by the need for large spaces ( $\geqslant 30$-m hallway for the $6 \mathrm{MWT}$ ), specific equipment (an audio tape for the shuttle walking test) and additional personnel (e.g. physiotherapists). Moreover, the quantification of ERD during 6MWT may be unreliable in some ILD patients [25] and the test may require an examiner to walk with the patient to increase safety. In contrast, the 6MST requires a portable single-stage step, which can be made available in any medical attending room. In addition, test monitoring is simpler and the number of steps climbed can be easily counted. This test, therefore, may allow exercise capacity and ERD to be determined during routine consultations to the physician with major advantages in terms of reducing costs and increasing the frequency of functional evaluations of ILD patients.

\section{Contrasting stepping versus cycling in ILD}

As submaximal cycling is frequently used to assess ERD, the present authors also compared the ventilatory and cardiovascular responses at the same metabolic stress in both exercise
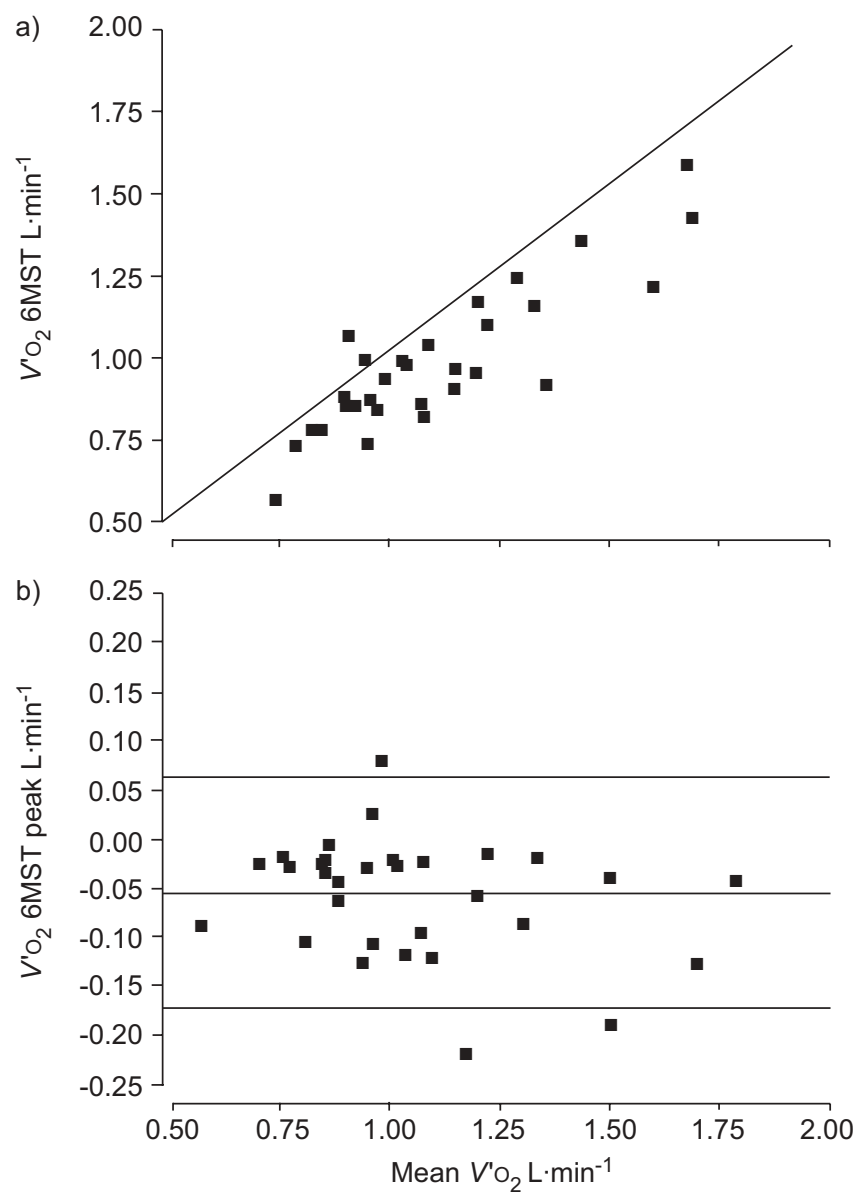

FIGURE 2. The 6-min step test (6MST) was related to a near-maximum metabolic stress as compared with maximal cardiopulmonary exercise tests: a) oxygen uptake $\left(\mathrm{V}^{\prime} \mathrm{O}_{2}\right)$ values were close to the line of identity; and b) a BlandAltman analysis revealed a narrow 95\% confidence interval for the between-test differences. $\longrightarrow$ : mean bias $\pm 1.96 \mathrm{sD}$.

modalities. However, the muscle mass involved in upright exercise is clearly larger than that in stationary cycling. Assuming a linear relationship between muscle mass and cardiac output, it is likely that patients needed to increase oxygen extraction during cycling to maintain the same $V^{\prime} \mathrm{O}_{2}$ of the 6MST. Moreover, the WR per unit of muscle mass is likely to be higher during cycling as compared to upright exercise [26]. As a consequence, the lactate production/clearance ratio is also higher at a given submaximal $V^{\prime} \mathrm{O}_{2}$ in this exercise modality. In fact, a trend to higher $V^{\prime} \mathrm{CO}_{2}$ and respiratory quotient was observed during cycling as compared with 6MST, which is consistent with an earlier lactate threshold during cycling; this was also previously found in patients with COPD [27-29].

In this context, PALANGE et al. [27] found that ERD was more prominent in walking than cycling and POULAIN et al. [30] demonstrated that the 6MWT was more sensitive than cycling to induce ERD in patients with COPD. Interestingly, this was also the case for some of the patients in the present study, especially when the 6MST was compared to CPETmax (table 2). As previously mentioned, upright exercise is likely to be 
associated with lower mixed venous oxygen saturation and higher cardiac output than cycling, two factors known to conspire against the homeostasis of intrapulmonary gas exchange in ILD patients. In addition, upright exercise may have a higher impact on pulmonary gas exchange inefficiency (i.e. higher dead space volume/VT) due to differences in body posture, lung volumes and/or central haemodynamics [27].

\section{Study limitations}

Stepping was not compared to treadmill or walking tests in the present study; it is therefore conceivable that patients' maximum potential for ERD was not reached. Pulse oximetry was used to follow exercise oxygenation levels. Although this is a clinically valid alternative, it should be recognised that signal reliability and stability decreases markedly with readings $<80 \%$ [31]. In the present study, however, only two patients showed such low levels of $\mathrm{Sp}, \mathrm{O}_{2}$ (fig. 1). Future studies involving more severe patients should assess whether pulse oximetry remains reliable during stepping exercise. It also remains to be determined whether the test is an acceptable strategy of exercise evaluation in more severe patients. In fact, the present study did not include patients receiving long-term oxygen therapy because they would be likely to need supplemental oxygen during exercise and $V^{\prime} \mathrm{O}_{2}$ was a relevant study outcome. Additionally, further studies should be performed to investigate whether the test is sensitive to interventions in fibrotic ILD, such as supplemental oxygen.

\section{Conclusions}

A single-stage, self-paced 6-min step test was able to provide reliable and reproducible estimates of exercise capacity and oxyhaemoglobyn desaturation in patients with stable, mild-tomoderate interstitial lung disease. The test may prove to constitute an inexpensive and portable method for the routine functional evaluation of the patient population in primary care.

\section{REFERENCES}

1 Hansen JE, Wasserman K. Pathophysiology of activity limitation in patients with interstitial lung disease. Chest 1996; 109: 1566-1576.

2 Harris-Eze AO, Sridhar G, Clemens RE, Zintel TA, Gallagher CG, Marciniuk DD. Role of hypoxemia and pulmonary mechanics in exercise limitation in interstitial lung disease. Am J Respir Crit Care Med 1996; 154: 994-1001.

3 Chetta A, Marangio E, Olivieri D. Pulmonary function testing in interstitial lung diseases. Respiration 2004; 71: 209-213.

4 American College of Sports Medicine. Guidelines for Exercise Testing and Prescription. 4th Edn. Philadelphia, Lea and Febiger, 1997.

5 Shapiro A, Shapiro Y, Magazanik A. A simple test to predict aerobic capacity. J Sports Med Phys Fitness 1976; 16: 209-214.

6 Bolliger CT, Perruchoud AP. Functional evaluation of the lung resection candidate. Eur Respir J 1998; 11: 198-212.

7 Hadeli KO, Siegel EM, Sherrill DL, Beck KC, Enright PL. Predictors of oxygen desaturation during submaximal exercise in 8,000 patients. Chest 2001; 120: 88-92.

8 Swinburn CR, Wakefield JM, Jones PW. Performance, ventilation, and oxygen consumption in three different types of exercise test in patients with chronic obstructive lung disease. Thorax 1985; 40: 581-586.

9 Casas A, Vilaro J, Rabinovich R, et al. Encouraged 6-min walking test indicates maximum sustainable exercise in COPD patients. Chest 2005; 128: 55-61.

10 Balfour-Lynn IM, Prasad SA, Laverty A, Whitehead BF, Dinwiddie R. A step in the right direction: assessing exercise tolerance in cystic fibrosis. Pediatr Pulmonol 1998; 25: 278-284.

11 American Thoracic Society/European Respiratory Society. International Multidisciplinary Consensus Classification of the Idiopathic Interstitial Pneumonias. Am J Respir Crit Care Med 2002; 165: 277-304.

12 Mahler DA, Wells CK. Evaluation of clinical methods for rating dyspnea. Chest 1988; 93: 580-586.

13 Pereira CAC, Barreto SP, Simões JG, Pereira FWL, Gerstler JG, Nakatani J.. Valores de referência para a espirometria em uma amostra da população brasileira adulta. [Reference values for spirometry in Brazilian adults.]. J Pneumol 1992; 18: 10-22.

14 Neder JA, Andreoni S, Castelo-Filho A, Nery LE. Reference values for lung function tests. I. Static volumes. Braz J Med Biol Res 1999; 32: 703-717.

15 Neder JA, Andreoni S, Peres C, Nery LE. Reference values for lung function tests. III. Carbon monoxide diffusing capacity (transfer factor). Braz J Med Biol Res 1999; 32: 729-737.

16 Neder JA, Nery LE, Castelo A, et al. Prediction of metabolic and cardiopulmonary responses to maximum cycle ergometry: a randomised study. Eur Respir J 1999; 14: 1304-1313.

17 Neder JA, Nery LE, Andreoni S, Sachs A, Whipp BJ. Oxygen cost for cycling as related to leg mass in males and females, aged 20 to 80. Int J Sports Med 2000; 21: 263-269.

18 ATS Committee on Proficiency Standards for Clinical Pulmonary Function Laboratories. ATS statement: guidelines for the six-minute walk test. Am J Respir Crit Care Med 2002; 166: 111-117.

19 Marciniuk DD, Gallagher CG. Clinical exercise testing in interstitial lung disease. Clin Chest Med 1994; 15: 287-303.

20 Moloney ED, Clayton N, Mukherjee DK, Gallagher CG, Egan JJ. The shuttle walk exercise test in idiopathic pulmonary fibrosis. Respir Med 2003; 97: 682-687.

21 Nishiyama O, Taniguchi $\mathrm{H}$, Kondoh $\mathrm{Y}$, et al. Health-related quality of life in patients with idiopathic pulmonary fibrosis. What is the main contributing factor? Respir Med 2005; 99: 408-414.

22 Hawrylkiewicz I, Izdebska-Makosa Z, Grebska E, Zielinski J. Pulmonary haemodynamics at rest and on exercise in patients with idiopathic pulmonary fibrosis. Bull Eur Physiopathol Respir 1982; 18: 403-410.

23 King TE Jr, Tooze JA, Schwarz MI, Brown KR, Cherniack RM. Predicting survival in idiopathic pulmonary fibrosis: scoring system and survival model. Am J Respir Crit Care Med 2001; 164: 1171-1181.

24 Lama VN, Flaherty KR, Toews GB, et al. Prognostic value of desaturation during a 6-minute walk test in idiopathic interstitial pneumonia. Am J Respir Crit Care Med 2003; 168: 1084-1090.

25 Eaton T, Young P, Milne D, Wells AU. Six-minute walk, maximal exercise tests: reproducibility in fibrotic 
interstitial pneumonia. Am J Respir Crit Care Med 2005; 171: 1150-1157.

26 Richardson S, Hardman AE. Endurance fitness and blood lactate concentration during stepping exercise in untrained subjects. Br J Sports Med 1989; 23: 190-193.

27 Palange $\mathrm{P}$, Forte S, Onorati P, Manfredi F, Serra P, Carlone S. Ventilatory and metabolic adaptations to walking and cycling in patients with COPD. J Appl Physiol 2000; 88: 1715-1720.

28 Christensen CC, Ryg MS, Edvardsen A, Skjonsberg $\mathrm{OH}$. Effect of exercise mode on oxygen uptake and blood gases in COPD patients. Respir Med 2004; 98: 656-660.
29 Troosters T, Vilaro J, Rabinovich R, et al. Physiological responses to the 6-min walk test in patients with chronic obstructive pulmonary disease. Eur Respir J 2002; 20: 564-569.

30 Poulain M, Durand F, Palomba B, et al. 6-minute walk testing is more sensitive than maximal incremental cycle testing for detecting oxygen desaturation in patients with COPD. Chest 2003; 123: 1401-1407.

31 Hannhart B, Michalski H, Delorme N, Chapparo G, Polu JM. Reliability of six pulse oximeters in chronic obstructive pulmonary disease. Chest 1991; 99: 842-846. 